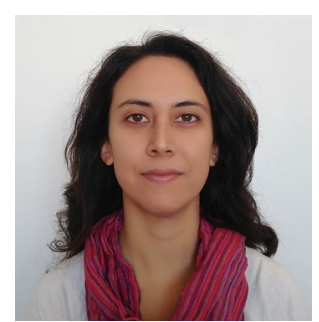

Credit: Elisa Mari Akagi Jordão

\section{PhDs in Brazil are perishing even when they publish}

\author{
Brazil's university landscape has undergone dramatic changes in recent decades, leading \\ to increased pressure to publish despite stripped resources. Elisa Jordão argues that this \\ makes it all the more important to educate the public about the value of scientific research \\ and education.
}

1 n 1987, the year I was born, 1,000 people received a $\mathrm{PhD}$ in Brazil. In 2017, this number had ballooned to about 20,000 people. Many agree that public investment in education and science are intricately linked and necessary to develop a country's autonomy. Since 2000, there has been a fivefold increase in international scientific publications in Brazil, accompanied by an almost fivefold increase in the number of graduate students. The number of new principal investigators in federal and state universities has increased threefold, and today $65 \%$ of them have a PhD. Authorship of publications by graduate students has also grown significantly. However, financial investment in science grew by only $72 \%$.

While scientific productivity and the number of graduate students have undergone massive growth, the increase in investment in scientific research has not been to scale. In 2016, scholarship amounts were the lowest since 1996, taking into account corrections for inflation. Today, a $\mathrm{PhD}$ student receives on average US \$564 a month, less than half as much as in 1996 when adjusted for inflation. One reason for the increase in publications is that under these conditions, $\mathrm{PhD}$ students depend on papers to remain competitive for the few opportunities on offer.

Another issue is that the rapid and substantial increase in the number of publications was not accompanied by an increase in impact. Brazil's scientific production, as measured by number of citations, is historically below world average despite an increase of $15 \%$ between 2011 and 2016. This low impact could be due to different factors, such as areas of research, lack of cutting-edge techniques or low originality because of the high pressure to publish. But that does not mean that Brazil's science is bad. On the contrary, we have a very good reputation in areas such as ecology, mathematics and neuroscience. In fact, Brazil was one of the few countries in which the percentage of papers accepted for publication increased between 2012 and
2017, suggesting an increase not only in volume, but also quality.

The pressures on Brazil's PhD students are not decreasing with Brazil's economy, which has been shrinking since 2013. Since 2016, federal spending on higher education has dropped sharply, with cuts of around $30 \%$ to maintenance funds and $70 \%$ to investment; the public budget for research and development has suffered cuts exceeding $28 \%$, and scholarships funds have been cut by $25 \%$. For graduate students this is worrisome because these cuts increase competition for scholarships. Publishing is almost a requirement for getting a scholarship, yet offers no guarantee of funding. Financial cuts also reduce the purchasing and maintenance of equipment and consumables. Therefore, even $\mathrm{PhD}$ students who win a scholarship may not have enough money to actually do their research. Financial insecurities together with high pressure to publish could be related to the alarming mental health issues among graduate students.

After finishing a $\mathrm{PhD}$, the situation does not improve: a new graduate may now be very qualified, but unemployed. In 2014, the percentage of $\mathrm{PhD}$ graduates in formal employment was only 75\%. This number may decrease given governmental austerity measures. Motivated by the prospect of working in excellent institutions, $\mathrm{PhD}$ graduates are competing for temporary jobs at universities where they may earn only US $\$ 475$ a month. The selection process is hard and competition is fierce for careers in universities. People are getting more qualified, which is a good thing, but when papers are more important to selection committees than other skills and attributes, this creates a problem. Publications are a parameter used in almost all decision-making in science, and we could lose scientific autonomy when doing that blindly. When you are pressured to publish, perhaps you might think twice before researching a challenging topic or very specific local issues that may be less likely to get accepted for publication. Besides, publishing skills alone do not make a great scientist. Of course we should publish-that is an essential part of science-but intellectual and cultural autonomy means we must be independent of such control tools. Other aspects should be regarded as equally relevant, such as dissemination of Brazilian science, teaching and organizing courses, and participating in scientific debates and decisions.

Now more than ever, Brazilian society needs to understand science to value what we do as scientists. This will not be achieved solely on the back of publications. Science in Brazil is facing a new challenge. For the first time, the government is verbally attacking public institutions of education and science, trying to justify budget cuts by questioning their quality and productivity. Together with financial cuts, this disregard for science is putting everything that Brazil has already built at risk, especially because Brazil has huge inequalities in resource distribution among its many regions.

Although my future in academia is uncertain, just as the future of science and education in Brazil are, this gives me more motivation to continue working and fighting for public science and education development. In May 2019, tens of thousands of people went twice into the streets around the country to protest against financial cuts in education and science, and I was there both times. Participation in social projects can give society power and a voice; my main interest now is bridging communication between public schools and neuroscience so that researchers and teachers can exchange knowledge and improve students' learning. This is a challenge that can only be overcome with cooperation and solidarity between many people.

Elisa Mari Akagi Jordão Department of Physiology, Institute of Biosciences, University of São Paulo, São Paulo, Brazil. e-mail: elisa.jordao@usp.br

Published online: 10 October 2019 https://doi.org/10.1038/s41562-019-0723-2

Competing interests

The author declares no competing interests. 